\title{
Scenarios for the future of the European process industry - the case of the chemical industry
}

\author{
Inga-Lena Darkow • Heiko A. von der Gracht
}

Received: 23 January 2013 / Accepted: 29 April 2013 / Published online: 24 September 2013

(C) The Author(s) 2013. This article is published with open access at Springerlink.com

\begin{abstract}
Will the European manufacturing industry survive in the long term? This question has been discussed for decades. The issue is particularly controversial for the chemical industry with its energy-intensive production and unpleasant image in European cities. We studied future challenges for the European chemical industry until the year 2030. Based on a Delphi survey in real-time format, we compiled the perspectives of 38 experts from industry, academia and government concerning 15 projections. The results were analysed according to the likelihood of occurrence, the impact and the desirability of the projections. Based on the 249 qualitative statements made by the participating experts, we derived four future scenarios. The scenarios address developments in sustainability and the dependency of the industry on oil in the future. Our research contributes to understanding the challenges that the chemical industry in Europe will face in the future, as well as which competitive advantages will contribute to its success.
\end{abstract}

Keywords Delphi survey . Chemical industry . Sustainability $\cdot$ Europe $\cdot$ Scenarios $\cdot$ Oil

\begin{abstract}
The presented research at hand is based on public available material and a survey conducted at EBS Business School, Wiesbaden, Germany. It is not intended to reflect the view of any chemical company or industry organization.
\end{abstract}

\section{I.-L. Darkow}

Department of Business Studies and Economics,

University Bremen, 28359 Bremen, Germany

e-mail: darkow@uni-bremen.de

H. A. von der Gracht $(\bowtie)$

EBS Business School, EBS Universität für Wirtschaft und Recht, Konrad-Adenauer-Ring 15, 65187 Wiesbaden, Germany

e-mail: heiko.vondergracht@ebs.edu

\section{Introduction}

Europe has a rich industrial history, which has supported the proliferation of manufacturing in various industries. Almost 250 years after the steam engine was improved by James Watt in Birmingham, thereby driving the Industrial Revolution, the manufacturing industry is still an essential part of the European economic system. Nevertheless, the European manufacturing industry has experienced numerous challenges over the past 30 years: Globalisation and competition from low-cost countries are certainly major drivers of change. Additionally, green and environmentally oriented non-governmental organisations (NGOs), concerned citizens and attentive consumers, supported by politicians willing to address voters' concerns about pollution and safety, raise relevant questions with regard to manufacturing practices. In many countries, the service sector seemed to be more favoured by government officials. This trend was transferred to regional economic policies during the previous decades. These developments have led to large investments in the service sector and a growing share of services in the gross domestic product of many, especially western and northern, European countries. However, only Germany seems to have continued to support its domestic expertise in the automotive, machinery, electronics, consumer goods and chemical industries.

Therefore, it is worthwhile creating scenarios based on expert views in order to develop future perspectives on the European industry. In this research paper we will show an academically sound approach based on the Delphi Method for creating multi-stakeholder scenarios. We include $38 \mathrm{ex}-$ perts from industry, academia and government concerning 15 projections.

In particular, the chemical industry has been a focal point for the public, government officials and non-governmental organisations due to its enormous consumption of energy and resources in production, its pollution potential and safety risks. Among the top concerns are the risk of polluting air, 
rivers and soil due to production failures and product spills. Therefore, citizens and communities in Europe are very cautious in allowing the chemical industry to invest in new sites or to enlarge existing sites. Non-governmental organisations closely monitor chemical companies in order to inform the public about any possible harm to the environment or human health.

However, the chemical industry supports economic growth in Europe considerably with $€ 539$ billion revenue in 2011, approximately $19.6 \%$ of worldwide chemical sales. In 2011, the chemical industry employed 1.19 million people across Europe and accounted for the highest labour costs per employee in the European Union. The main production sites are located in Belgium, France, Italy, Switzerland, Great Britain and Spain, whereas Germany is the largest producer in Europe, accounting for $29 \%$ of European chemical sales. The world's largest chemical company and the largest chemical site, BASF, is located in Germany. Most customer industries of the chemical industry are also located in Europe, for example consumer goods, automotive, construction, energy, health care, food and agriculture. The EU industry recorded modest growth of $1.4 \%$ in production volume in the year 2011 and $0.9 \%$ during the last 5 years. The European chemical industry consumed 7.3 million tonnes of oil and overall 54 million tonnes of oil including gas and electricity in 2010 [1].

In the previous decade, the basic chemical industry grew tremendously in Asia, the Middle East and South America. In addition, production capacities for specialty chemicals are on the rise in Asia. Many customer industries continue moving towards Asia in order to satisfy the growing demand of large populations with larger disposable incomes [2]. Some customer industries are dominant in Asia, for example the textile and consumer electronics industries, and trigger a large demand for chemicals in this region. The access to resources, workforce, feedstock and energy willingly offered by state-owned energy companies supports investments of multinational chemical companies in China, Malaysia and India, to name just a few countries. This might indicate a shift of production capacities towards this region. At the same time, petrochemical state-controlled companies are trying to move down the value stream and have started producing basic chemicals, intensifying the competition in these commodity-oriented markets. Governmental institutions support these developments with complementary regulations and trade barriers, such as the necessity to establish joint ventures with domestic players when entering a market [3]. These developments might indicate a changing competitive environment in these regions, making it more difficult for non-domestic players to create a competitive advantage [4-7].

The chemical industry has always had to manage uncertainties and risks due to the very nature of its business: First, compared to materials and ingredients provided by nature and used by mankind for thousands of years, we have limited knowledge about the impact of chemical products on humans and the environment since they have only been used for a few centuries [8]. Second, handling and treating chemicals in raw material procurement, production, distribution and (re-)use require expertise and awareness of risks involved. Therefore, managing and assessing risks and uncertainties are key topics for chemical companies and governmental institutions to prevent human beings, public health and the natural environment from being harmed by toxic emissions and product spills. Environmental, health and safety precautions are on the agenda of corporate senior management and heeded in daily operations in every chemical plant and supply chain partner. Risk assessment in the chemical industry is highly regulated in Europe, as in many other regions and countries of the world, in order to protect public health [9]. European regulations are based on national regulations and registration, evaluation and authorisation of chemicals (REACH). New laws have been initiated in the European chemical industry for REACH [10]. In addition, the industry is committed to own safety measures with product stewardship programmes and responsible care initiatives [11].

The entire chemical industry plans for the long-term future. The aforementioned risk management initiatives are long-term obligations. Moreover, investments in production facilities and plants are capital intensive. Therefore, the return on investment is rather long term compared to other industries [7]. Furthermore, the industry is exposed to changes in the value chain over time: Customers and society have become more aware of sustainability issues, e.g. protecting the natural environment and healthy nutrition; certain resources have become scarce; industry regulations have become complex; global competition has risen and the market is as volatile as any other industry. For these reasons, the industry applies sophisticated planning methods, for example the scenario approach, in order to anticipate long-term developments and uncertainties, as seen in the example of Shell $[12,13]$ and BASF $[14,15]$. Vecchiato [16] shows in his research how the chemical industry addresses its complex business environment with foresight activities. Companies utilise scenarios in order to create corporate strategies, which are flexible and robust and consider internal and external aspects [17]. Here, the foresight work is the basis for strategy development and implementation, as explained by Voros [18] and detailed by Rohrbeck and Schwarz [19].

We address the following research question in this paper: How will the chemical industry in Europe evolve in the future, and what key risks and uncertainties will be involved? We proceed by examining previous publications concerning trends and uncertainties in the European chemical industry in order to develop a research framework. After explaining how the Delphi method was applied to collect empirical data from 38 experts and managers in the chemical industry, we develop four future scenarios based on the 249 comments made by the participants. 
These scenarios address industry developments in sustainability and oil dependency, which we identified as main drivers of change and source of uncertainty for the chemical industry in Europe. We conclude the article by highlighting limitations to our research and providing ideas for further research.

\section{Literature review and research framework}

In examining previous publications concerning trends and uncertainties in the European chemical industry and companies' use of scenarios, it becomes apparent that most recent studies have been published by international consulting companies. Accenture provided trends and an overview of the European chemical industry's future by evaluating 29 end markets for chemicals, e.g. healthcare, agriculture, construction, automotive, food and beverages, and industrial equipment [3]. Based on the growth projections per industry by Eurostat, the analysis shows the sales forecasts in these markets. The Accenture experts concluded that the total revenue for the European chemical industry will increase from $€ 317$ billion in 2010 to $€ 477$ billion in 2030 .

Moreover, this study addresses the shift of manufacturing to China and other emerging markets. Based on previous globalisation efforts and changes in value chains, the customer industries of the European chemical market are in a good shape: Production in Europe is less dependent on labour costs due to automation and robotics. This trend shall continue for the next decade. Furthermore, industries in emerging markets will need knowledge in technologies and markets in order to develop their chemical industries further downstream. European chemical companies could support this need and invest in emerging economies. For China, an investment of European petrochemical players of $€ 2.7$ billion in plants is expected until 2030. The competition with players from the Middle East, relying on rather cheap raw material costs, will lead European chemical companies to focus on specialty chemicals, new products and services based on efficient supply chains covering high growth regions in Europe. A clear overview of the market is the key to success and involves creating innovations, advancing knowhow, attracting talent, providing solutions and concentrating on large domestic customers. The Accenture report concludes that the European chemical industry will still exist in 2030 and will largely resemble the competitive situation of today. In order to do so, specific customer needs, in terms of solutions and supply chain services, need to be served. Industry success will depend on efficient asset utilisation, innovative manufacturing technology, effective business processes and dedicated talent management.

Heinzelbecker [15] published insights about scenarios in the chemical industry based on a scenario development process of the European Chemical Industry Council (Cefic). He drew attention to structural changes in the chemical industry. External driving forces are addressed, including globalisation of customer industries, increasing cost pressures especially on commodities, strong pressure to increase shareholder value, new technological challenges and constraints to improve sustainability. Moreover, internal processes of adaptation will include the creation of transnational chemical companies, focus on core competencies, increased mergers and acquisitions, spin-offs and joint ventures as well as advancements in biotechnology and genetic engineering. Heinzelbecker explained a comprehensive scenario approach applied by various European chemical organisations to develop two types of scenarios: three top-down scenarios and two bottom-up scenarios. The topdown approach covers powerful growth, profitable growth and missed opportunities as scenarios based on workshops with industry experts and facilitated by a software package called Think Tools, now called EIDOS. Based on the feedback on the published top-down scenarios and with a similar method, three specific bottom-up scenarios were developed for petrochemicals, plastics chemicals and specialty chemicals. Finally, the author presents another four scenarios developed by Cefic in order to explain European authorities the future prospects of the chemical industry in Europe. The applied methodology consists mainly of a strong global database of economies and industries provided by Global Insights and their econometric modelling. Additional workshops, supported by Think Tools, were used in order to develop the chemical scenarios. Heinzelbecker concluded that the topic of innovation appears as a key driver in the various European chemical industry scenarios.

In 2011, the consulting company Deloitte published more specific scenarios: "Chemical Logistics Visions 2020" which were supported by Cefic [20]. Based on workshops with Cefic members and desk research conducted by Deloitte, key trends, their impacts and possible solutions were identified. Three chemical industry scenarios were developed: dislocation, transition and resilience, covering the macroeconomic perspective. Based on these scenarios, more specific and logistics-relevant implications and possible solutions were derived. The study additionally emphasises risks and uncertainties, such as greenhouse gas emission regulations, safety and security topics (e.g. terrorism) or urbanisation, and their impact on chemical logistics.

ATKearney [21] provided its perspective of the long-term future of the chemical industry in "Chemical Industry Vision 2030: A European Perspective". The white paper provides trends and strategic suggestions for European chemical companies based on the market knowledge of the consulting company. The study projects chemical value chains to shift eastward, an increase in state-controlled companies, new and large players from emerging markets, as well as more volatile and less predictable economic conditions. These developments might lead to a change in the direction of trade flow. The guiding projections include the "ruler strategy" as the most likely scenario for 
European chemical players, including the absence of disruptive events, and the continuity of recent trends. This will lead to an Asian dominance in chemical markets by 2030 due to customer industries requiring diverging needs in a multi-polar industry landscape. Nevertheless, European companies are encouraged to defend their home markets, to establish markets with growth potential and innovative products and to develop skills and resources to stay competitive - even in the Asian markets. The authors conclude by urging companies to prepare for various scenarios and to develop agility along the value chain.

A KPMG report provided insights into the current and future states of the European chemical industry [7]. One projection made in the report is more dramatic than any other projections made in future-related papers: The study predicts that by $2015,26 \%$ of the European steam cracker capacity is expected to be dispensable, and 14 out of 43 crackers will be rendered uneconomic due to capacities in emerging markets. The steam cracker is the first chemical processing plant in the value chain, which cracks naphtha into other molecules, i.e. breaking long-chain hydrocarbons into short ones, which will be used for the next steps in the chemical processing. These steam crackers are supposed to be the "heart" of basic chemical production, require high investments and are in focus when evaluating capacity utilisation of a chemical plant. Nevertheless, this white paper mainly explores the current state of the chemical industry in Europe. European chemical companies will continue to be challenged by competitors from the Middle East and Asia and need to maintain their lead with regard to innovations and customer collaborations.

In light of these challenges, the future of the chemical industry in Europe is uncertain: Many trends and uncertainties will have an impact on main players and their business environments. These market forces can be structured into five clusters, according to Porter [4]. The first force is based on new market entrants. In the European chemical industry, these might be Asian-located multinational companies and state-controlled players from China or the Middle East. Furthermore, new players in specialty chemicals using non-oil raw materials and production technologies will cause market turbulence. In general, high entry barriers exist in the chemical industry due to high investment needs in production technologies and processes as well as high regulation and documentation requirements $[5,6]$.

The second market force relates to substitutes for products. As the chemical industry is mainly driven by economies of scale for basic chemicals and by economies of scope in the specialty chemicals business, substitutes seem to be rather unlikely. However, the rise of non-oil raw materials might lead to new products, which could serve as substitutes for existing products.

Third, the bargaining power of customers is primarily product related and niche related. The industry is highly interrelated, with supplier-buyer relationships changing over time, possibly even leading to reverse relationships due to raw material shortages or production breakdown in a plant. Swap business is very common for commodities among the large chemical players in Europe; for instance, products are directly shipped from a competitor to a customer or from a plant to the competitor's customer in order to reduce transportation and handling costs.

The fourth force reflects the bargaining power of suppliers. As the chemical industry relies on oil and naphtha - the first production step after oil - the raw materials are mainly commodities traded on spot markets. Therefore, the bargaining power of suppliers is rather limited. Furthermore, pipeline connections often used between suppliers and buyers reduce the degrees of freedom for both supply chain partners as the costs to change supply chain partners are rather high.

Finally, the fifth force addresses rivalry within the chemical industry. Although 12 out of 30 major players are headquartered in Europe, significant rivalry is not an issue in European markets [7]. These well-established companies have specialised competencies and capabilities, creating a stable market environment. However, the European chemical industry is dependent on access to feedstock from sources outside of Europe, which could cause the companies to compete for essential raw materials. Research and development is primarily conducted in Europe and North America, and is slowly advancing in Asia. Companies specialising in downstream or customer-oriented specialty markets are less driven by rivalry. An additional dimension that significantly influences the rivalry in the chemical industry is the political and social acceptance of chemical production due to the hazardous goods and risks involved. Therefore, the chemical industry in Europe will be highly influenced by the business environment created by political and societal forces.

In summarising the findings of our literature review, we focused on the factors shaping the macro-economic and industry-specific business environment for the chemical industry. We identified 15 key factors that will determine the future of the European chemical industry, based on the analyses of previous studies (see Table 1). These 15 factors establish our research framework in order to analyse in more detail the future of the chemical industry in Europe.

Each of the five aforementioned studies covers 9 to 13 of these factors, with ATKearney covering the most comprehensive set of factors. A (growing) volatile business environment is mentioned by ATKearney [21] only. Shifting R\&D eastward and a global diffusion of market and technology knowledge is only mentioned by ATKearney [21] and Accenture [3], and adjusting to customer-specific needs is addressed by KPMG [7] and Accenture [3]. Maintaining know-how and attracting talent and increasing regulation and activism, e.g. in risks and safety, are mentioned by three studies. The other ten factors are addressed by at least four or even all five studies. Projections which are addressed by all studies are more pressure to develop 
Table 1 Literature review on factors determining the future of the European chemical industry

\begin{tabular}{|c|c|c|c|c|c|}
\hline Factors influencing future developments & Heinzelbecker [15] & KPMG [7] & Deloitte and Cefic [20] & ATKearney [21] & Accenture [3] \\
\hline $\begin{array}{l}\text { Shift of chemical production and demand to Asia } \\
\text { and the Middle East }\end{array}$ & Yes & Yes & Yes & Yes & Yes \\
\hline $\begin{array}{l}\text { Increasing cost pressure and (oil) price volatility, } \\
\text { esp. on commodities }\end{array}$ & Yes & Yes & Yes & Yes & No \\
\hline Volatile business environment & No & No & No & Yes & No \\
\hline Moving down the value chain & No & Yes & Yes & Yes & Yes \\
\hline $\begin{array}{l}\text { Pressure to innovate products, services, manufacturing } \\
\text { technologies and business processes }\end{array}$ & Yes & Yes & Yes & Yes & Yes \\
\hline $\begin{array}{l}\text { Shifting R\&D to Asia; global diffusion of market and } \\
\text { technology knowledge }\end{array}$ & No & No & No & Yes & Yes \\
\hline Domestic advantage of European companies continues & Yes & Yes & No & Yes & Yes \\
\hline $\begin{array}{l}\text { New market players from the Middle East and Asia, } \\
\text { state-controlled companies due to access to cheap } \\
\text { raw materials }\end{array}$ & No & Yes & Yes & Yes & Yes \\
\hline $\begin{array}{l}\text { Consolidation of chemical industry by mergers } \\
\text { and acquisitions and alliances }\end{array}$ & Yes & Yes & Yes & Yes & No \\
\hline Increasing demand for customer-specific solutions & No & Yes & No & No & Yes \\
\hline Sustainability-orientation & Yes & Yes & Yes & No & Yes \\
\hline Focus on asset utilisation and core competencies & Yes & Yes & No & Yes & Yes \\
\hline Maintaining know-how and attracting talent & No & Yes & No & Yes & Yes \\
\hline Regulation and activism, e.g. in risks and safety & Yes & No & Yes & Yes & No \\
\hline $\begin{array}{l}\text { Commitment to organic feedstock, substitution } \\
\text { of oil-based products }\end{array}$ & Yes & Yes & Yes & Yes & Yes \\
\hline
\end{tabular}

and sustain competitive advantage in the Asian markets due to the shift towards Asia and Middle East, pressure on innovation in products, services, manufacturing technologies and business processes and engagement in bio feedstock and substitution of oil-based products.

We can conclude that future-oriented reports and studies of international consulting companies with chemical divisions suggest remarkably certain future developments: the three consulting companies provide only one scenario for the chemical future of Europe. Nevertheless, Heinzelbecker [15] and Deloitte \& Cefic [20], with its logistics focus, provide different scenarios for analysing the European chemical industry. Although the chemical industry is powerful and the petrochemical industry is a pioneer for scenario planning, recent scientific publications about these topics are rather difficult to find.

\section{Delphi methodology}

The research method section explains the use of the Delphi method for collecting empirical data from 38 experts and managers in the EU chemical industry and how to create expert-based scenarios. The Delphi technique is an anonymous, written and multi-round survey procedure, where a designated expert panel discusses future developments in the form of projections [22, 23]. This method is suitable for situations with high uncertainty and where expert knowledge is the only source of data [24]. During the past decades, the technique has been used across all disciplines and industries and for many different purposes, among which forecasting has taken a dominant role, as indicated by Rowe and Wright in their introduction to a special issue on the topic [25]. The technique's major aim is to efficiently structure group communication while overcoming negative psychological constraints, e.g. halo and bandwagon effects, common in traditional face-to-face communication [26]. The Delphi process may lead to consensus among the expert panel [23], although some Delphi studies also focus on dissent and more controversial debates [27-31]. In recent years, numerous scholars have employed the Delphi method to collect a profound database for scenario development and enrich scenario creation while taking multiple stakeholder perspectives into account [32]. We followed such a Delphi-based scenario process, where the Delphi survey was conducted in realtime format in order to streamline the process and reduce negative effects of conventional paper-based Delphi studies, such as long processing time or participation effort [33-35].

\section{Development of projections}

In order to develop projections, or concise and provoking statements of the future, for our Delphi survey, we followed a two-stage process. First, we conducted intensive database 
research and reviewed literature to identify relevant factors concerning the future of the EU chemical industry and to extract factors considered to influence it. In addition, we interviewed six experts from research centres and chemical companies located in Europe to complement earlier research. In the second step, we transformed the identified factors into Delphi projections. Our target was to keep the processing time to complete the questionnaire as short as possible in order to reduce potential research fatigue, which could negatively impact data validity. In this context, we followed the recommendations made by Parentè and Anderson-Parentè [36] not to exceed 25 projections. A draft including 15 projections was formulated in short, descriptive, provocative propositions, describing possible future states relevant to the European chemical industry for the year 2030 [37]. The projections were presented to two academics and two practitioners in the field, who checked the projections' wording for potential ambiguity and content validity. Based on their feedback, we revised the projections accordingly. The final 15 projections including their short titles are summarised in Table 2.

Most of the identified factors were directly translated into one specific projection, e.g. the factor "sustainability orientation" was translated into the projection 15 "2030: Sustainability has become a key corporate value of European chemical companies". In order to make the Delphi participants aware about the long-term-perspective, each projection started with the year " 2030 ". In order to provoke a clear reaction of the Delphi panel, some literature-based factors were translated in more specific statements about the state of the future, e.g. the factor "increasing cost pressure and (oil) price volatility, esp. on commodities" was translated into the two projections 6 " 2030 : The oil dependency of the European chemical industry has decreased significantly" and 9 "2030: Synthetic materials have drastically reduced the global need for the mining of metals (e.g. gold, iron, copper)". Other factors were bundled into one projection in order to limit the number of statements which needed to be evaluated by the survey participants. Therefore, projection 7 "2030: All European production activities have been relocated to outside of the EU" is based on three factors: "shift of chemical production and demand towards Asia \& Middle East", "shifting research \& development towards Asia; global diffusion of market \& technology knowledge" and "focus on asset utilisation and core competencies".

During the Delphi survey, each projection was assessed in relation to its probability of occurrence (expected probability, EP) (scale from 0 to $100 \%$ ), impact on the chemical industry (I) (five-point Likert scale) and desirability of occurrence (D) (five-point Likert scale). Furthermore, all experts were asked to provide (optional) explanations of their answers. Directly after providing their initial assessments, experts received a feedback of the aggregated group opinion and had the opportunity to revise their earlier estimates based on the new information. The survey process was conducted over 8 weeks.

\section{Expert selection and response analysis}

Delphi surveys do not strive for representativity in sampling, but for the highest possible degree of expertise $[25,26]$. Thus, the selection of experts for the Delphi panel is crucial and significantly influences the reliability of research results $[38,39]$. We included experts from the fields of the European

Table 2 Projections of the Delphi survey

\begin{tabular}{ll}
\hline Projections & Short title \\
\hline 1. 2030: The uncertainty (i.e. the degree of complexity and dynamics) in the & Uncertainty \\
industry environment has increased. & Rules and regulations \\
2. 2030: Rules and regulations within the industry have been tightened. & Value chain \\
3. 2030: The value chain of the industry has fundamentally changed. & Industry attractiveness \\
4. 2030: The overall industry attractiveness has increased. & Radical innovations \\
5. 2030: Radical innovations have led to fundamental changes within the industry. & Oil dependency \\
6. 2030: The oil dependency of the European chemical industry has decreased significantly. & Production shift \\
7. 2030: All European production activities have been relocated to outside of the EU. & Value of image \\
8. 2030: Public pressure has made image a key value driver for chemical companies in the EU. & Synthetic materials use \\
9. 2030: Synthetic materials have drastically reduced the global need for the mining of metals & Recycled materials \\
(e.g. gold, iron, copper). & Qualified personnel shortage \\
10. 2030: High-performance materials are made completely out of recycled substances. & World hunger \\
11. 2030: The European chemical industry suffers from a dramatic shortage of qualified personnel. & Shift in raw material mix \\
12. 2030: Scientific breakthroughs in the chemical industry have eradicated world hunger. & Bio-based products \\
13. 2030: Resource scarcity has led to a shift in the raw material mix used in the chemical industry. & Value driver sustainability \\
14. 2030: Bio-based products have created a paradigm shift in chemical production. & \\
15. 2030: Sustainability has become a key corporate value of European chemical companies. &
\end{tabular}


chemical industry, governmental institutions and politicians as well as media representatives based on their designated and documented knowledge and expertise, as well as their capacity, willingness and time to participate [40]. Overall, 371 experts within the $27 \mathrm{EU}$ member states were contacted by phone and/or email. All invited industry experts were at senior management level. The sample comprised experts from the entire value chain of the chemical industry including service providers, suppliers, retailers and other partners.

The Delphi portal was open for 8 weeks, during which each expert could access the portal as often as he or she desired in order to follow the discussion process, revise own estimates or add comments. During the survey process, multiple reminders to participate were sent. Finally, 38 experts $(10.0 \%$ response rate) completed the survey. The average number of logins was 2.0 times per expert, while 249 comments were provided, equalling an average of 6.7 comments per expert. The expert panel represented seven EU countries. Figure 1 illustrates the response rate per stakeholder group.

\section{Scenario development based on Delphi results}

The Delphi data were used as input for scenario development. We followed the scenario axes technique, where two uncertainties are plotted along two axes in order to derive four (extreme) scenarios by combining the different end points of the axes [41-43]. This process was enriched by the expert comments and desk research. The axes were based on the Delphi projections 6 (oil dependency) and 15 (value driver sustainability). The technique helps to broaden the perspectives and contrasts the probable projections obtained from the Delphi data. Each of the four scenarios was given a challenging and provocative title. Furthermore, all information was integrated

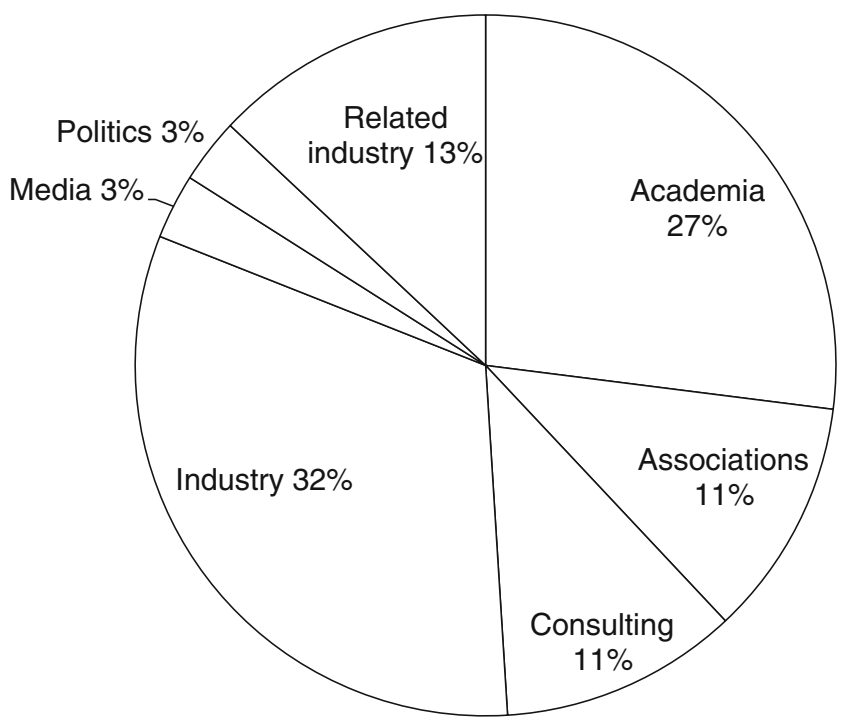

Fig. 1 Representation of stakeholder groups among participants into a narrative story, which describes a possible and plausible situation in the future of the European chemical industry.

\section{Results and discussion}

We constructed our scenarios in a systematic way following a multistage process. First, we conducted a quantitative analysis of the Delphi data including the calculation of mean values for the probability of occurrence and impact dimension. Further, we analysed the standard deviations in estimates and checked whether the Delphi process leads to convergence (decrease in standard deviation over Delphi rounds), or in achieving consensus among experts. We calculated interquartile ranges (IQR) of experts' assessments, which can be used as an indicator for consensus measurement [23, 44, 45]. Consensus was achieved, if a projection scored an interquartile range of below 20 .

Second, we clustered our projections into strategic groups based on the probability of occurrence and impact. The clustering allowed for interpretation of degree of strategic relevance and inclusion in strategic planning processes.

Third, we coded the qualitative data of the Delphi survey. By doing so, we were able to enrich scenario texts with qualified expert assessments. Table 3 summarises the quantitative results of the research. The combination of these three steps including quantitative and qualitative data analysis supports deriving image of the future of the chemical industry in Europe.

The results of our Delphi survey demonstrate the entire range of assessment possibilities with the Delphi method. Some projections result in rather high expected probability (82-84 \%). Projection 2 (rules and regulation) and projection 15 (value driver sustainability) belong to this group of highimpact prospects, indicating a high likelihood that these two events will occur: they are expected projections. Stricter rules and regulations (projection 2) received the highest expected probability within the Delphi survey.

The second group of projections, the high-impact expectations, shows a rather high expected probability (57-72\%). However, the expert panel did not reach consensus for most items, as the IQR was between 20 and 35. Projection 1 (uncertainty) is among the projections in this cluster, indicating the lowest IQR of only 10 within the whole sample. The majority of projections belong to this group: 3 (new value chain), 5 (radical innovations), 6 (oil dependency), 8 (value of image), 11 (qualified personnel), 13 (shift in raw material mix) and 14 (bio-based products).

Projections with medium expected probability (42-52\%), rather high IQR (18-40) and a high impact on the industry in case of occurrence (3.6-3.9) are summarised as high-impact eventualities. Projection 4 (industry attractiveness), 9 (synthetic material use) and 10 (recycled materials) are part of this group. In addition, projection 12 (world hunger) can be classified as a medium-impact eventuality since it scores a 
Table 3 Delphi survey results for the chemical industry panel

\begin{tabular}{|c|c|c|c|c|c|c|}
\hline No. & Projections for 2030 & EP final & SD change & IQR & $I$ & $D$ \\
\hline 1 & $\begin{array}{l}\text { The uncertainty (i.e. the degree of complexity and dynamics) } \\
\text { in the industry environment has increased. }\end{array}$ & $72.5 \%$ & -20.0 & 10 & 3.8 & 2. \\
\hline 2 & Rules and regulations within the industry have been tightened. & $84.2 \%$ & -8.0 & 22 & 4.1 & 3.0 \\
\hline 3 & The value chain of the industry has fundamentally changed. & $58.0 \%$ & -8.4 & 20 & 3.7 & 3.1 \\
\hline 4 & The overall industry attractiveness has increased. & $52.5 \%$ & -5.2 & 30 & 3.8 & 4.1 \\
\hline 5 & Radical innovations have led to fundamental changes within the industry. & $56.7 \%$ & -9.0 & 22.5 & 3.8 & 4.0 \\
\hline 6 & The oil dependency of the European chemical industry has decreased significantly. & $59.1 \%$ & +0.6 & 40 & 3.9 & 3.7 \\
\hline 7 & All European production activities have been relocated to outside of the EU. & $26.7 \%$ & -7.1 & 30 & 4.0 & 1.9 \\
\hline 8 & Public pressure has made image a key value driver for chemical companies in the EU. & $66.1 \%$ & -9.2 & 30 & 3.6 & 3.2 \\
\hline 9 & Synthetic materials have drastically reduced the global need for the mining of metals & $41.8 \%$ & -14.6 & 17.5 & 3.6 & 3.6 \\
\hline 10 & High performance materials are made completely out of recycled substances. & $49.9 \%$ & -3.1 & 40 & 3.6 & 3.9 \\
\hline 11 & The European chemical industry suffers from a dramatic shortage of qualified personnel. & $61.1 \%$ & -11.1 & 35 & 4.2 & 1.7 \\
\hline 12 & Scientific breakthroughs in the chemical industry have eradicated world hunger. & $38.6 \%$ & -7.3 & 35 & 3.4 & 4. \\
\hline 13 & Resource scarcity has led to a shift in the raw material mix used in the chemical industry. & $69.0 \%$ & -3.7 & 30 & 4.0 & 3. \\
\hline 14 & Bio-based products have created a paradigm shift in chemical production. & $58.6 \%$ & -5.3 & 30 & 3.8 & 3. \\
\hline 15 & Sustainability has become a key corporate value of EU chemical companies. & $82.6 \%$ & -8.1 & 17.5 & 3.9 & 4 \\
\hline
\end{tabular}

Projections in italics: consensus achieved: IQR $\leq 20$

$E P$ estimated probability of occurrence (0-100 \%), I impact (five-point Likert scale), $D$ desirability (five-point Likert scale), IQR interquartile range for EP ratings, $S D$ standard deviation for EP ratings

lower expected probability (39\%) and also a lower impact on the industry (3.4). Finally, projection 7 (shifting European production to other regions) has the lowest expected probability (27\%) within the Delphi survey, but one of the highest impacts (4.0), which classifies it as a high-impact surprise.

All projections revealed a decrease in the standard deviation (SD) over Delphi rounds. This indicates a convergence process, i.e. the agreement among the panel increases. Interestingly, projection 6 (oil dependency) shows an increasing SD, which indicates an increasing level of disagreement. This result marks it as special and crucial for further analysis, which took place in the scenario axes exercise.

The expert opinions converged for all Delphi projections. Our cluster analysis revealed structures and similarities in the Delphi data. We included the mean values of EP and impact (I) of each Delphi projection. Previous research has found that such clustering is particularly supportive in deriving appropriate actions and strategies [46-48]. Figure 2 presents the results of our cluster analysis. Diamonds indicate projections with consensus among the panel, while triangles represent a dissent.

Overall, we were able to identify five meaningful clusters for probability of occurrence and impact: "high-impact prospects", "high-impact expectations", "high-impact eventualities", "medium-impact eventualities" and "high-impact surprises". For each cluster, strategic implications for market players are different. High-impact prospects indicate that companies, as well as governmental institutions, need to be prepared for stricter rules and regulations and sustainability being a key value driver. These issues are well reflected in the literature $[3,7,15,20,21]$. Most studies and publications indicate that this future is very likely, implying that every market player needs to be prepared for these developments. Being not prepared is a rather risky strategy, which might lead to losing the "licensee to operate". The same might be true for high-impact expectations. However, here players should be more selective depending on their market positioning. For example, radical innovations, shift in raw material mix and bio-based products within the industry will most probably not affect all market players in the same way [15]. High-impact eventualities provide a rather less clear guideline for the market. Their expected probability is too low in order for it to be necessary to prepare for these situations. Nonetheless, companies should monitor the market intensively with regard to overall attractiveness of the industry, also for talent, and the use of recycled and synthetic materials. With a more general view on the chemical industry, Vecchiato [16] draws attention to the very complex business environment with a multitude of drivers, which are interrelated. Therefore, our findings are in line with literature $[3,7,21]$, but provide more specific insights into the relevance and uncertainty of drivers for future developments.

The medium-impact eventuality can be perceived as an outlier in our sample: world hunger was eradicated due to chemical innovations. Even though it is rather unlikely and its impact is rather low for the entire industry, this future state might be interesting for a limited number of players, e.g. providers of chemicals for the agricultural sector. Finally, one 


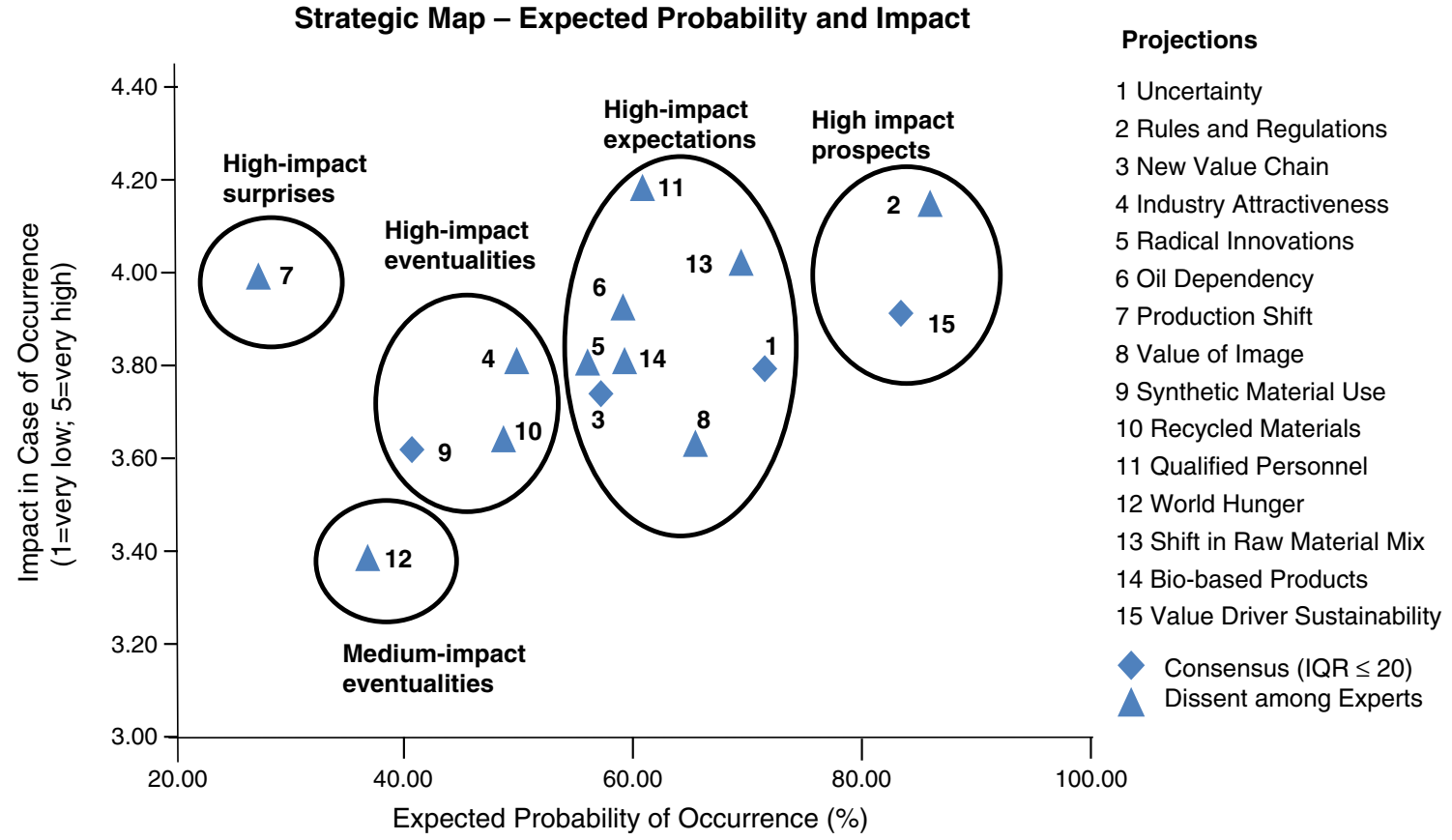

Fig. 2 Clustered future projections

surprise emerged in our Delphi survey: the projection about the complete shift of chemical production towards non-European countries. The arguments provided by the experts show that the customer industries will remain strong and grow in Europe by 2030. Therefore, the chemical supply market including production is likely to remain in the same region. Moreover, the longterm investments, highly skilled labour, research and development capabilities and infrastructural conditions will support the chemical industry in Europe. This statement is supported by the research of Accenture [3] as well.

In essence, the results demonstrate controversial evaluations of the projections. Only four projections: 1 (uncertainty), 3 (new value chain), 9 (synthetic material use) and 15 (value driver sustainability) resulted in consensus among the Delphi panel. The desirability of the projections also seems to be interesting. Projection 12 about eradicating world hunger through chemical innovations has received the highest value of 4.4 within the Delphi survey, followed by projection 15 about the value driver sustainability (4.3). At the other end of the scale are projection 11 (qualified personnel) and 7 (production shift) with 1.7 and 1.9 as desirability values.

\section{Development of Delphi-based scenarios}

We find that experts still feel quite uncertain since numerous probability values of approximately $50 \%$ emerged. Furthermore, most projections did not show consensus, which also demonstrates the ambivalence of the expert panel. In order to further address this uncertainty, more extreme scenarios were developed using the scenario axes technique [41-43]. Based on the data of our Delphi survey, we selected projection 6 (oil dependency) and projection 15 (value driver sustainability) as input. Projection 6 is the only one which did not converge during the Delphi process, indicating very diverse discussion and evaluation of the topic. Projection 15 achieved consensus ( $\mathrm{IQR}=17.5)$ and has the second highest expected probability of $83 \%$, which underlines the high degree of certainty among experts.

We used our two driving forces in order to create four scenario quadrants by combination of the axes' poles. The results of the qualitative data analysis were used to conduct reasonable scenario writing. Figure 3 shows the scenario axes and scenarios.

The following four scenarios present possible situations for the European chemical industry in the future based on the evaluation of the Delphi experts:

In the year 2030, the chemical industry is still highly dependent on oil and naphtha as essential raw materials for producing most of its products. Initiatives for promotion of alternative energy sources were not as expected even though the European chemical industry invested in research for alternative raw material use and production technology. Chemical production knowledge is not limited to mature markets only, but globally diffused. European companies are not able to compete with state-owned Middle Eastern and Asian companies or shelf-oil-based US companies with access to cheap feedstock. Crude oil consumption can be satisfied due to additional oil reserves being discovered. Moreover, cheaper exploration technologies are used by the 
Fig. 3 Scenarios on the future of the European chemical industry 2030

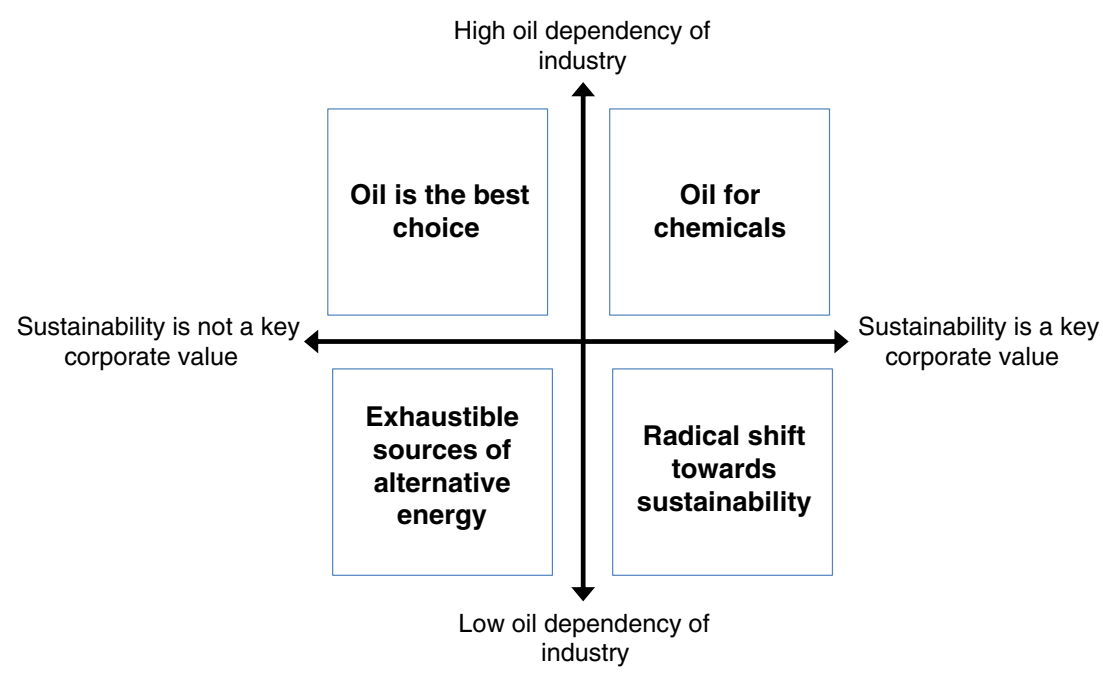

incentives for researchers maintained innovation knowledge within Europe until today. Unfortunately, many of the substitute raw materials are also exhaustible. Therefore, the European chemical industry can be described as "exhaustible sources of alternative energy".

Finally, scenario four presents a world of low oil dependency and strict sustainability orientation within the chemical industry. Due to changing and volatile customer requirements, all European industries were forced to create sustainable value chains, including chemical materials in all forms. Housing, heating, mobility, nutrition and even electronic products started to rely heavily on sustainable ingredients. This development was made possible by innovative companies, which experimented with non-oil-based materials and manufacturing processes. After initial positive results, the industry applied the new technologies and used these raw materials because consumers were willing to pay a premium for sustainable sources. European regulation supported the development and used sustainability orientation as a trade barrier to cheap imports from the Americas and Asia. Europe has become a "green island" due to its "radical shift towards sustainability".

\section{Conclusion}

The aim of our research was to examine how the future of the chemical industry in Europe will evolve and what the key risks and uncertainties will be. To answer this question in a systematic and valid way, a Delphi survey with 38 industry experts, academics and government officials was conducted. Projections about possible future states of the industry in 2030 were derived from literature, our research framework and database research and evaluated during a real-time Delphi survey. A strategic map with prospects, expectations, eventualities and surprises, which might shape the European chemical industry in the future, was developed. Thereafter, 
four extreme scenarios based on 249 comments of the Delphi participants were developed concerning two key issues: sustainability and oil dependency of the industry.

The main insights of our research and scenarios are that sustainability will play a vital role in the future, not only as an economic factor, but also for corporate image considerations. Resource scarcity will dominate the industry in the future even more than today, and alternative sources of feedstock for production processes will be essential. The majority of the experts in our Delphi panel evaluate the scenario "oil for chemicals" as the most likely one. Nevertheless, the ability of the industry to reduce its dependency on oil remains uncertain. More stringent rules and regulations will influence the industry's ability to compete on a global scale. A lack of qualified personnel poses one of the most serious threats. Overall, the European chemical industry faces a rather uncertain future in terms of complexity and dynamics, but a total production shift away from Europe seems to be unlikely.

The number of issues considered in our survey was somewhat limited. Certainly, the future of the European chemical industry will be influenced by more factors than included in this study. Future research might examine topics, such as customer orientation and solution-based business, infrastructure, technologies, or risks. Furthermore, we focused on experts from Europe to discuss the future of the European chemical industry. Extending the expert panel, e.g. Asia, the Americas, Middle East and Africa, would also be useful for managers and governments to evaluate the global perspective. Future research could also include a focus on "wildcards": rather unlikely events which could have significant impact on the industry, for example steam cracker breakdowns, zero emission controls and devastating conflicts between the Eastern and Western countries. Also we found quite a number of projections to result in dissent on their probability. Future research might concentrate on dissent (see, e.g. [30, 31]) or more explorative analyses (see, e.g. [49]) in the field.

With this research, we contribute to a vision of Europe with a prosperous and strong chemical industry, which is key element of the economic landscape of Europe. The European chemical industry will most likely be a part of European as well as global value chains, as customer industries will have their manufacturing sites in Europe in 2030. However, the European chemical industry needs to be aware of and to adapt to significant trends. Rules and regulations will dominate the "licensee to operate" even more so than they did during the previous decades. Volatility in the markets will add further challenges to manage the chemical value chain. The public, represented by government officials, nongovernmental organisation and governmental institutions, will not accept risks to public health or the natural environment. Consequently, the sustainability requirement will be one of the key value drivers in the future. This trend is linked to the management of scarce resources, such as oil and other raw materials. The European chemical industry can prepare for the future by investing early in sustainable options and alternatives, focusing on specialty products, continuously promoting research and development, as well as developing specialists and supporting education.

All of these aspects require the capability to identify, project, and manage long-term future developments. Here, not only business needs to be involved, but also educational and research institutions, as well as national and European political systems. Economic and legislative stability and reliability will provide the fundament for economic success. On the other hand, the European chemical players will need to become involved in discussions about new legislation in order to be prepared for the future and develop strategies to compete globally. They will need to be engaged in sustainability and talent initiatives in order to shape the future according to the various stakeholder needs. Although the future is uncertain, the experts envision a competitive and prosperous future for the chemical industry in Europe.

Acknowledgments We would particularly like to thank Stefan Katz, Andreas Schneller and Robin Wagner for inspiring and thoughtful discussions as well as for data collection and support in scenario creation. Furthermore, we would like to thank Janice Magel for proofreading and support in finalising the manuscript.

Open Access This article is distributed under the terms of the Creative Commons Attribution License which permits any use, distribution, and reproduction in any medium, provided the original author(s) and the source are credited.

\section{References}

1. The European Chemical Industry Council (2012) Facts and figures 2012: the European chemicals industry in a worldwide perspective. Cefic-The European Chemical Industry Council, Brussels

2. OECD (2010) The emerging middle class in developing countries (working paper no. 285). OECD, Paris

3. Accenture (2011) Looking ahead to 2030: a review of trends and influencers in the European Chemical Industry. Accenture, Houston

4. Porter ME (2008) The five competitive forces that shape strategy. Harv Bus Rev 86(1):78-93

5. World Economic Forum (2012) The global enabling trade report 2012: reducing supply chain barriers. WEF, Geneva

6. German Chemical Industry Association (VCI) (2012) The German Chemical Industry in 2030 - a summary of the VCI Prognos study. VCI, Frankfurt

7. KPMG (2010) The future of the European Chemical Industry. KPMG, London

8. Schörling I (2003) The greens perspective on EU chemicals regulation and the white paper. Risk Anal 23(2):405-409. doi:10.1111/ 1539-6924.00320

9. Goldstein BD (2011) Risk assessment of environmental chemicals: if it ain't broke.... Risk Anal 31(9):1356-1362. doi:10.1111/j.15396924.2010.01447.x

10. The European Parliament (2006) Registration, evaluation, authorisation and restriction of chemicals (REACH). REGULATION (EC) No 1907/2006. The European Parliament, Brussels 
11. ICCA (2006) Responsible care: global charter. Cefic, Brussels

12. Schoemaker PJH, van der Heijden CAJM (1992) Integrating scenarios into strategic planning at Royal Dutch/Shell. Plan Rev 20(3):41-46. doi:10.1108/eb054360

13. van der Heijden K (1997) Scenarios, strategy, and the strategy process. Presearch — provoking strategic conversation (GBN) 1(1):1-32

14. Heinzelbecker $K$ (2005) Future management in the chemical industry. In: Neef A, Burmeister K (eds) In the long run. oekom, Munich, pp $171-175$

15. Heinzelbecker K (2005) Futuring in the chemical industry. J Bus Chem 2(1):37-53

16. Vecchiato R (2012) Environmental uncertainty, foresight and strategic decision making: an integrated study. Technol Forecast Soc Chang 79(3):436-447. doi:10.1016/j.techfore.2011.07.010

17. Amit R, Schoemaker P (1993) Strategic assets and organizational rent. Strateg Manag J 14(1):33-46. doi:10.1002/smj.4250140105

18. Voros J (2003) A generic foresight process framework. Foresight 5(3):10-21. doi:10.1108/14636680310698379

19. Rohrbeck R, Schwarz JO (2013) The value contribution of strategic foresight: insights from an empirical study of large European companies. Technol Forecast Soc Chang. doi:10.1016/j.techfore.2013.01.004

20. Deloitte, Cefic (2011) Chemical logistics vision 2020: the next decade's key trends, impacts and solution areas. Deloitte, London

21. ATKearney (2012) Chemical industry vision 2030: A European perspective. ATKearney

22. Rowe G, Wright G (2001) Expert opinions in forecasting: the role of the Delphi technique. In: Armstrong JS (ed) Principles of forecasting: a handbook for researchers and practitioners. Kluwer Academic, Boston, pp 125-144

23. von der Gracht HA (2012) Consensus measurement in Delphi studies: review and implications for future quality assurance. Technol Forecast Soc Chang 79(8):1525-1536. doi:10.1016/j.techfore.2012.04.013

24. Linstone HA, Turoff M (1975) Introduction. In: Linstone HA, Turoff M (eds) The Delphi method-techniques and applications. Addison-Wesley, Reading, pp 3-12

25. Rowe G, Wright G (2011) The Delphi technique: past, present, and future prospects - introduction to the special issue. Technol Forecast Soc Chang 78(9):1487-1490. doi:10.1016/j.techfore.2011.09.002

26. Linstone HA, Turoff M (2011) Delphi: a brief look backward and forward. Technol Forecast Soc Chang 78(9):1712-1719. doi:10.1016/ j.techfore.2010.09.011

27. Turoff M (1970) The design of a policy Delphi. Technol Forecast Soc Chang 2(2):149-171. doi:10.1016/0040-1625(70)90161-7

28. Steinert M (2009) A dissensus based online Delphi approach: an explorative research tool. Technol Forecast Soc Chang 76:291-300

29. van de Linde E, van der Duin P (2011) The Delphi method as early warning: linking global societal trends to future radicalization and terrorism in the Netherlands. Technol Forecast Soc Chang 78(9):1557-1564. doi:10.1016/j.techfore.2011.07.014

30. Tapio P (2003) Disaggregative policy Delphi: using cluster analysis as a tool for systematic scenario formation. Technol Forecast Soc Chang 70(1):83-101. doi:10.1016/S0040-1625(01)00177-9

31. Warth J, von der Gracht HA, Darkow I-L (2012) A dissent-based approach for multi-stakeholder scenario development - the case of the future of electric drive vehicles. Technol Forecast Soc Chang 80(4):566-583. doi:10.1016/j.techfore.2012.04.005
32. Nowack M, Endrikat J, Guenther E (2011) Review of Delphi-based scenario studies: quality and design considerations. Technol Forecast Soc Chang 78(9):1603-1615. doi:10.1016/j.techfore.2011.03.006

33. Gnatzy T, Warth J, von der Gracht HA, Darkow I-L (2011) Validating an innovative real-time Delphi approach - a methodological comparison between real-time and conventional Delphi studies. Technol Forecast Soc Chang 78(9):1681-1694. doi:10.1016/j.techfore.2011.04.006

34. Gordon TJ, Pease A (2006) RT Delphi: an efficient, "round-less" almost real time Delphi method. Technol Forecast Soc Chang 73(4):321-333. doi:10.1016/j.techfore.2005.09.005

35. Geist MR (2010) Using the Delphi method to engage stakeholders: a comparison of two studies. Eval Program Plan 33(2):147-154. doi:10.1016/j.evalprogplan.2009.06.006

36. Parentè FJ, Anderson-Parentè JK (1987) Delphi inquiry systems. In: Wright G, Ayton P (eds) Judgemental forecasting. Wiley, Chichester, pp 129-156

37. Loveridge D (2002) On Delphi questions (ideas in progress). The University of Manchester, Manchester

38. Hasson F, Keeney S (2011) Enhancing rigour in the Delphi technique research. Technol Forecast Soc Chang 78(9):1695-1704. doi:10.1016/j.techfore.2011.04.005

39. Kastein MR, Jacobs M, van der Hell RH, Luttik K, Touw-Otten FWMM (1993) Delphi, the issue of reliability: a qualitative Delphi study in primary health care in the Netherlands. Technol Forecast Soc Chang 44(3):315-323. doi:10.1016/0040-1625(93)90075-I

40. Adler M, Ziglio E (1996) Gazing into the Oracle: the Delphi method and its application to social policy and public health. Jessica Kingsley Publishers, London

41. van't Klooster SA, van Asselt MBA (2006) Practicing the scenario-axes technique. Futures 38(1):15-30. doi:10.1016/j.futures.2005.04.019

42. Schwartz P (1991) The art of the long view: planning for the future in an uncertain world. Doubleday, New York

43. van der Heijden K (1996) Scenarios: the art of strategic conversation. Wiley, Chichester

44. Scheibe M, Skutsch M, Schofer J (1975) Experiments in Delphi methodology. In: Linstone HA, Turoff M (eds) The Delphi method-techniques and applications. Addison-Wesley, Reading, pp 262-287

45. De Vet E, Brug J, De Nooijer J, Dijkstra A, De Vries NK (2005) Determinants of forward stage transitions: a Delphi study. Heal Educ Res 20(2):195-205. doi:10.1093/her/cyg111

46. Akkermans HA, Bogerd P, Yücesan E, van Wassenhove LN (2003) The impact of ERP on supply chain management: exploratory findings from a European Delphi study. Eur J Oper Res 146(2):284-301. doi:10.1016/S0377-2217(02)00550-7

47. Ogden JA, Petersen KJ, Carter JR, Monczka RM (2005) Supply management strategies for the future: a Delphi study. J Supply Chain Manag 41(3):29-48. doi:10.1111/j.1055-6001.2005.04103004.x

48. Rikkonen P, Kaivo-Oja J, Aakkula J (2006) Delphi expert panels in the scenario-based strategic planning of agriculture. Foresight. J Futur Stud Strateg Think Policy 8(1):66-81. doi:10.1108/ 14636680610647156

49. Kuusi O (1999) Expertise in the future use of generic technologies. Epistemic and methodological considerations concerning Delphi studies. Helsinki School of Economics and Business Administration, Helsinki 